\title{
La Actitud de la Obra de ARTe
}

THE WORK-OF-ART STANCE

\author{
MALENA LEÓN \\ Instituto de Humanidades (CONICET-Universidad Nacional de Córdoba), ARGENTINA \\ malena.leon.m@gmail.com
}

\begin{abstract}
We aim to develop a take on the meaning of works of art that builds on Dennett's view on the nature of intentionality, namely, that the intentionality exhibited by mental phenomena is not original, but derived. Regarding the meaning of works of art, theories that hold that the meaning is determined by the intentions of the author when creating the work are considered intentionalist. Adopting the view of derived intentionality implies that it is no longer possible to maintain that the semantic content of a work of art is closely linked to the creative act that gave rise to it; accordingly, intentionalist theories should be, broadly speaking, abandoned. However, we claim that one aspect of intentionalist theories is accurate and, moreover, compatible with the perspective on intentionality we adopt: The fact that part of the meaning of a work of art is given by the interpretations that arise when it is assumed that the work was produced by an agent with the purpose of transmitting something. We call this interpretative strategy the work-of-art stance and argue that it should be understood as a subtype of the intentional stance. According to our proposal, this interpretive strategy is part of a view that tries to explain the meaning of works of art as partially indeterminate, relative to a history (and not to a foundational origin) and dependent on interpretive attribution.
\end{abstract}

Keywords: Derived intentionality • intentionalism • meaning of the work of art $\bullet$ Daniel Dennett

Una de las razones por las que la disputa en estética sobre la relevancia de las referencias a las mentes e intenciones de los artistas ha sido tan intratable es que esa disputa descansa en problemas de filosofía de mente que son igualmente intratables.

Lyas 1992, p.137, nuestra traducción

\section{Introducción}

En su intento de explicar el contenido mental, Dennett (1998 [1987]) asignó especial relevancia a la discusión filosófica sobre la naturaleza de la intencionalidad, entendida 
como la propiedad distintiva de ciertos fenómenos que consiste en ser acerca de o estar dirigidos a otros fenómenos. En otros términos, que algo sea intencional quiere decir que posee contenido semántico. ${ }^{1}$

Hay, a su vez, diferentes tipos de fenómenos que exhiben intencionalidad. Usualmente se afirma que las cogniciones, percepciones, acciones son intencionales. Pero, por otra parte, la intencionalidad también es portada por afirmaciones, símbolos públicos y artefactos como mapas o programas de computadora. Según la concepción inaugurada por Brentano (1995 [1874]), el modo en el que estos dos grupos de fenómenos exhiben intencionalidad es diferente. De acuerdo con esta diferenciación, los segundos tendrían intencionalidad sólo de modo derivado, esto es, la heredarían de otro fenómeno que ya tendría ese rasgo, trazándose, así, una distinción entre un tipo de intencionalidad que es considerada original y otra que es derivada. Por su parte, Dennett, propuso debatir los fundamentos de esta distinción. Apoyándose en argumentos evolucionistas, sostuvo que toda forma de intencionalidad es derivada. Llamaremos a la teoría dennettiana acerca del contenido mental una perspectiva de la intencionalidad derivada.

Ahora bien, este debate ha sido abordado primordialmente teniendo en cuenta sus consecuencias para entender las mentes humanas - es decir, aquel tipo de entidades que poseerían intencionalidad intrínseca一, dejando fuera de consideración sus efectos en relación con aquellas entidades que sólo poseen intencionalidad derivada: paradigmáticamente, los productos culturales. Si desde una perspectiva clásica se entiende que el contenido intencional de una producción cultural está dado por ciertas capacidades del agente intencional que la concibió y realizó, es pertinente la pregunta de si una nueva concepción de la naturaleza de la intencionalidad -i.e., una que no mantenga la distinción entre intencionalidad intrínseca y derivada- no da lugar, de manera análoga, a una nueva forma de entender el contenido intencional de dichos productos.

En este marco se torna interesante retomar la discusión clásica acerca del significado (o el sentido) de las obras de arte. La discusión hermenéutica tuvo un auge importante a mediados del siglo XX cuando se produjo una suerte de reacción a la crítica literaria "biograficista", que se concentraba más bien en estudiar la vida de los autores antes que las obras mismas, dado que se consideraba a estas últimas como un reflejo de la vida mental de sus creadores. Dicha idea es recuperada por teorías recientes, aunque bajo una elaboración más sofisticada. La corriente que las reúne recibe el nombre de intencionalismo ${ }^{2}$ (Carroll 1997, 2000; Currie 1995; Hirsch 1967a, 1967b; Levinson 1996; Tolhurst 1979; Wimsatt \& Beardsley 1946). Se consideran intencionalistas las teorías que sostienen que el significado de una obra de arte está determinado por las intenciones que tuvo su autor a la hora de crearla. Si bien esta discusión surge en el campo de la literatura, los argumentos y posiciones involucrados pueden ser aplicados a las obras de arte en general. Mientras que en el campo de 
la hermenéutica se han elaborado argumentos a favor y en contra de dicha perspectiva, la discusión parece estar escindida de la cuestión filosófica acerca de la relación entre el contenido de los estados mentales y el de los productos culturales.

En este trabajo pretendemos examinar las implicancias de adoptar una perspectiva de la intencionalidad derivada a la hora de elaborar una teoría sobre el contenido semántico de este tipo de objetos culturales, a saber, las obras de arte. Dado que dicha perspectiva cuestiona que los estados mentales sean la fuente última o "piedra de toque" del significado (por lo que Dennett, 1998, los compara con el motor inmóvil aristotélico), podría parecer que adoptar la perspectiva de la intencionalidad derivada implica que ya no es posible sostener que el contenido semántico de una obra de arte está vinculado al acto creativo que le dio origen. Así, parece congeniar bien con las posturas anti-intencionalistas, que señalan que el sentido de un texto o, más en general, de una obra, no está determinado por las intenciones de su creador. El mismo Dennett (1990) señala, con respecto a los textos y los artefactos técnicos en general, que el sentido y la función no dependen de las intenciones. Ahora bien, consideramos que llevar al extremo el anti-intencionalismo conduce a una concepción deficiente del sentido de las obras de arte. Para despertar esa intuición, presentaremos un experimento mental, al que de ahora en adelante referiremos como el experimento mental 'del gato montajista', que intenta mostrar por qué no se pueden dejar de lado las intenciones de los creadores a la hora de interpretar una obra de arte, al menos no en todos los sentidos. Sin embargo, también consideramos que la perspectiva de la intencionalidad derivada es incompatible con las distintas teorías intencionalistas disponibles, dado que todas mantienen una concepción cartesiana de lo mental, en un sentido que luego desarrollaremos. Así, habiendo recuperado algunas intuiciones intencionalistas que parecen adecuadas y, habiendo señalado en qué aspectos las teorías intencionalistas son, sin embargo, inadecuadas, estableceremos los fundamentos básicos sobre los que debería erigirse una teoría del significado de las obras de arte desde la perspectiva de la intencionalidad derivada. Defenderemos que las teorías del significado que adopten dicha perspectiva deben entender al significado como algo parcialmente indeterminado, relativo a una historia (y no a un origen fundacional) y dependiente de la atribución interpretativa. También defenderemos que esta atribución es de carácter múltiple y se produce en distintos niveles. Según el modelo que pretendemos mostrar, uno de estas atribuciones se realiza adoptando una estrategia interpretativa a la que llamaremos la actitud de la obra de arte, en alusión a la teoría de los sistemas intencionales de Dennett (1998) y a su propuesta de distinguir entre tres diferentes actitudes interpretativas: física, del diseño e intencional. La actitud de la obra de arte debe ser entendida como un subtipo de la actitud intencional y consiste en interpretar el "significado" de algunas entidades o comportamientos suponiendo que un agente los creó (produjo o realizó) intencionadamente, en el sentido de que tuvo el objetivo de transmitir algo. 
En el primer apartado de este artículo presentaremos el experimento mental del gato montajista, que pretende evidenciar que, respecto del sentido de una obra de arte, no parece plausible dejar completamente de lado una consideración respecto del acto creativo que le dio origen. En el siguiente apartado, realizaremos una escueta presentación de la concepción dennettiana de la intencionalidad y de su tesis de que toda intencionalidad es derivada. A continuación, dedicaremos un apartado a exponer una versión estándar de la teoría intencionalista del sentido de las obras de arte, la crítica que ha recibido por parte de Wimsatt \& Beardsley (1946) bajo el nombre de falacia intencional y algunas teorías intencionalistas recientes más sofisticadas. En el cuarto apartado pretendemos mostrar en qué medida la perspectiva de la intencionalidad derivada es incompatible con todas esas versiones del intencionalismo. Luego de señalar cuáles aspectos de las teorías intencionalistas eran dependientes de una concepción errónea de la intencionalidad, el quinto apartado estará destinado a elaborar los fundamentos de una teoría del sentido de las obras de arte que sea consecuente con la perspectiva de la intencionalidad derivada. Desde esta perspectiva, no se requiere que el sentido sea algo completamente determinado y es preciso, en cambio, que quien interpreta la obra de arte adopte, entre otras posturas interpretativas, lo que provisoriamente llamaremos la actitud de la obra de arte. En el último apartado explicaremos en qué consiste la estrategia interpretativa de la actitud de la obra de arte comparándola con estrategias similares, propuestas en artículos filosóficos recientes.

Por último, se podría considerar que la visión acerca del significado de las obras de arte que ofreceremos en este artículo presenta afinidades con el constructivismo. Las teorías constructivistas son aquellas según las cuales parte del significado de una obra de arte es construido, al menos parcialmente, por su público, en la interpretación. Sin embargo, las teorías que pueden recibir esta etiqueta son muy diversas entre sí (Gaut 2010, Capítulo 4). Por ese motivo, excede a este artículo ahondar en las similitudes y diferencias que la perspectiva que defendemos guarda con otras teorías constructivistas. Antes bien, dado que nuestro principal objetivo es trazar el vínculo entre la discusión en el campo de la filosofía de la mente y el lenguaje sobre la intencionalidad con la discusión sobre el sentido de los productos artísticos, las teorías a analizar serán las intencionalistas, bajo sus distintas versiones. ${ }^{3}$

\section{Un experimento mental sobre las intenciones: el gato montajista}

¿Las intenciones del creador determinan el sentido de una obra de arte? Consideramos que un buen punto de partida para abordar esta cuestión es imaginar qué sucedería si estuviésemos frente a un objeto que formalmente guarda muchas simili- 
tudes con una obra de arte, pero que carece de autor; en otros términos, que no es el resultado de una agencia intencional. Podría tratarse, por ejemplo, de un montaje de fragmentos de registro de video (o tomas) realizadas por una cámara de seguridad, de buena definición, situada a una altura aproximada a la de un adulto promedio. La selección y orden de los fragmentos habría sido realizada de forma completamente azarosa, por ejemplo, siguiendo las siguientes instrucciones:

1. Coloque un gato al frente de un reproductor de vinilos

2. Coloque un vinilo e inicie su reproducción sin poner la tapa protectora que va por encima

3. Deje que el gato, cautivado por los movimientos del vinilo, meta la patita frenándolo, cuantas veces quiera

4. Con ayuda de un cronómetro, anote en un papel la duración de cada uno de los periodos en los que el vinilo está girando y en los que está frenado

5. Multiplique por cinco la duración de los periodos de tiempo anotados y hágalos coincidir, superponiéndolos, con la duración del material de filmación

6. Utilice como fragmentos "seleccionados" aquellos que coincidan con los momentos en los que el vinilo estaba girando

7. Enumere los fragmentos "seleccionados"

8. Escriba la fecha de nacimiento del gato según el calendario chino

9. Utilice el orden de los dígitos que quedan como resultado del paso 7 para ordenar los fragmentos seleccionados ${ }^{4}$

¿Consideraríamos el resultado de este proceso una película? Presumiblemente, no. Ahora bien, al menos en términos formales, el resultado de este extraño experimento no tiene por qué ser muy distinto a películas que efectivamente existen: documentales observacionales, con planos fijos y sin trama narrativa. Dichos documentales son, sin lugar a dudas, películas; independientemente de la valoración o el interés que despierten en distintos tipos de espectadores.

Ahora bien, ¿dónde radica la diferencia entre ambos casos? Podría pensarse que el producto obtenido por medio del experimento del gato montajista será ostensiblemente arbitrario, mientras que en el caso de los documentales habrá una continuidad de sentidos patentes. Sin embargo, no es verdad que las películas documentales que estamos tomando como ejemplo tengan siempre líneas de sentido claras. Y, por otra parte, también es probable que el resultado del experimento contenga continuidades y sentidos inesperados. De este modo, ambos productos podrían poseer el mismo tipo de contenido. 
Si sostenemos que, aun así, hay una diferencia fundamental en el significado de estos productos y que la misma se debe a que uno fue creado por un agente intencional y el otro es un simple resultado de un proceso "ciego", parecemos estar concediendo un punto al intencionalismo, esto es, a la doctrina que sostiene que el significado de un texto o una obra de arte está dado por las intenciones de su creador o creadores. Si pensamos, en cambio, que ambos productos cuentan, potencialmente, con el mismo tipo de significado, con independencia del proceso que los haya originado, estamos del lado del anti-intencionalismo, que considera que el sentido de una obra de arte no tiene ningún vínculo con las intenciones de su creador. Antes de saltar hacia alguna de estas conclusiones tan rápidamente, proponemos un breve análisis de un documental de este tipo que creemos que puede ayudar a dilucidar las diferencias con el caso imaginado de la cámara de seguridad y el gato.

Nos referiremos a la película Austerlitz de Sergei Loznitsa (2016). Se trata de un documental observacional que transcurre en un campo de concentración, abierto al público como un memorial del holocausto. La película está conformada por la sucesión de extensos planos fijos generales en blanco y negro. La mayor cantidad del tiempo vemos gente recorriendo el parque con ropa de verano, gorras, lentes de sol, comida y muchas cámaras digitales. Este último aspecto también contribuye a la invisibilización del dispositivo que registra la película, dado que este (el dispositivo) parece ser una cámara entre otras que llevan los visitantes del memorial en sus teléfonos celulares y otras tecnologías de registro de imágenes, por lo cual, del mismo modo que ocurre con una cámara de seguridad cuando no se sabe que está allí, su presencia no altera el comportamiento de los visitantes. Los elementos formales y narrativos acercan bastante este objeto artístico (Austerlitz) al registro que se podría obtener, con algo de buena suerte, de nuestro experimento. Profundicemos un poco el análisis de la película real, con el objeto de determinar si los aspectos que encontramos en ella podrían también estar presentes en el producto imaginario.

Si nos atenemos a lo que muestran las imágenes, el contenido estricto del film consiste en exhibir gente (que podemos caracterizar como turistas) recorriendo un ex-campo de exterminio nazi. Sin embargo, no podemos evitar pensar que se nos está invitando a formular algún tipo de reflexión o sentimiento al respecto. La masa informe de turistas en el campo tiene comportamientos que, vistos desde la distancia que establece la cámara con ellos, resultan muy extraños. La gran mayoría de los visitantes se dedica a caminar, escuchar lo que dicen los guías y tomarse fotos. Algunos de ellos también están comiendo. Lo que salta a la vista fácilmente es que hay una especie de agrietamiento insuperable entre lo que un lugar como ese debería significar por haber sido escenario del horror en el pasado y el modo en el que los turistas se mueven actualmente en él. Ciertas decisiones cinematográficas nos hacen pensar que el autor de esta obra tiene una perspectiva acerca de lo que ahí ocurre. Una de ellas es la de filmar en verano, en una localidad en la que las altas tempe- 
raturas hacen que sea altamente probable que la ropa de la gente que circula sea muy informal. Otro ejemplo de estas decisiones es no incluir en la película la voz de ninguna de las personas a la que se nos invita a mirar. Podemos ver de lejos que los visitantes sacan fotos, caminan, comen, pero no sabemos qué dicen. En cambio, las únicas voces que se escuchan son las de los guías turísticos relatando situaciones de horror. Otro ejemplo de las decisiones cinematográficas tomadas por el director es la de montar estos relatos con comportamientos especialmente burdos por parte de los visitantes. Así, justo después de escuchar las pésimas condiciones alimenticias en las que se encontraban los prisioneros del campo, vemos un señor comiendo muy animosamente un emparedado.

Ahora bien, si nos atenemos a los aspectos formales, cada uno de los rasgos señalados en el párrafo anterior podría encontrarse en el resultado de un recorte azaroso de un registro realizado en forma automática por una cámara de seguridad como el que propone nuestro experimento mental del gato montajista. Sin embargo, cada uno de ellos adquiere otro significado en la medida en que pueden ser interpretados como decisiones. En definitiva, todos estos elementos están indicando que hay una suerte de mensaje relativo a la inadecuación entre, por una parte, los banales y descuidados comportamientos de los visitantes y, por la otra, los contenidos transmitidos sonora y visualmente acerca de la historia del espacio físico en el que ellos se mueven, que merecería un comportamiento más solemne y preocupado.

Es sensato hipotetizar que el resultado del experimento del gato montajista, también podría despertar en sus espectadores reflexiones similares a las que despierta Austerlitz; esto es, reflexiones acerca de la relación entre el comportamiento de las personas y lo inadecuado que este resulta para un espacio que funciona como museo de la memoria. Sin embargo, parece innegable que, si este contenido es presentado como un mensaje emitido por alguien, la interpretación del mismo adquirirá otras dimensiones. Por ejemplo, si es entendida como resultado de una agencia intencional, la idea de focalizarse en el comportamiento inadecuado de los visitantes, presentada de forma inteligente y con una belleza formal impecable despierta, en quién comparte el espíritu crítico del film, una sensación de complicidad de los espectadores con el realizador. También puede haber, entre quienes experimentaron esta crítica compartida hacia los visitantes del campo, una segunda reflexión en la que toman distancia del primer juicio emitido. Esta distancia podría deberse a que, si se entiende al contenido del film como un mensaje, el mismo parece tener un contenido meramente negativo: los espacios que deberían ser para la memoria no funcionan. En contrapartida, no hay ningún contenido propositivo acerca de lo que sí debiera hacerse. Según esto, podría pensarse que esta obra cinematográfica hace algo muy parecido a lo que está denunciando: utiliza un campo de concentración para sugerir que los comportamientos de las personas en espacios públicos masivos son bastante tontos. Así, podría pensarse que se trata de una película de actualidad sobre un campo de 
concentración que no busca despertar ninguna reflexión sobre la historia reciente de la humanidad, sino sólo mostrar que los humanos pueden comportarse de forma muy banal en determinados contextos. Un espectador que arribara a conclusiones de este tipo podría rechazar la mirada completamente negativa que propone la película, pero dejar abierta una reflexión sobre los vínculos que las sociedades establecen con los sitios que conmemoran grandes hitos históricos.

Independientemente de cuán adecuada o inadecuada sea la interpretación ejemplificada, lo que está claro es que una reflexión de ese tipo sólo es posible porque se entiende lo que se puede ver en la película no sólo como contenido acerca del mundo, sino, además, como un contenido que alguien ha decidido mostrar de ese modo por algún motivo. De acuerdo con esto, habría una diferencia en el tipo de significado que tienen los dos productos, en virtud de que uno de ellos fue realizado por alguien con determinados objetivos. Si tal intuición es adecuada, estaríamos en lo cierto al decir que el sentido de una obra de arte está vinculado con el hecho de que la misma se presenta como el resultado de una acción intencional. En este aspecto, los lineamientos de la teoría que defendemos en el presente artículo se acercan a los del intencionalismo. Sin embargo, se distancia de las teorías intencionalistas más conocidas respecto de su concepción sobre la intencionalidad.

\section{La perspectiva de Dennett sobre la intencionalidad}

Dennett considera que no tenemos más motivos para sostener la distinción entre intencionalidad original y derivada que nuestras arraigadas, pero no fundamentadas creencias de sentido común acerca de la naturaleza de nuestra mente (cfr. Dennett 1990, p.106). En los distintos textos en los que aborda el tema recurre a un experimento mental o "bomba de intuición" que tiene como objeto mostrar que no tenemos buenas razones para sostener que los seres humanos somos diferentes, en los aspectos relevantes, a robots a los que nos negaríamos a atribuir intencionalidad original.

El experimento presentado por Dennett $(1998,1990,1995)$ invita a imaginar que un ser humano tiene el deseo de ver cómo es el mundo en el año 2401 y las tecnologías disponibles permiten cumplir ese deseo si la persona está dispuesta a ser congelada y permanecer en estado comatoso durante todos esos años. Para cuidar el cuerpo, se construye un robot que sea resistente, autosustentable energéticamente y que tenga la posibilidad de trasladarse. Además, se debería proveer al dispositivo de cierta capacidad de autocontrol, que le permita derivar metas subsidiarias vinculadas al objetivo final de preservar el cuerpo, en función de los distintos contextos. El resultado del diseño será un robot con cierto grado de autocontrol, que, mientras persigue el objetivo final de auto-preservación del organismo en su interior, se verá involucrado en distintos proyectos (muchos de los cuales pueden terminar resultando contraproducentes para los objetivos de sus diseñadores). Parece sensato 
sostener que, sin embargo, el robot sólo tendría intencionalidad derivada, no tomaría verdaderamente decisiones. Ahora bien, la tesis de Dennett es que la misma consideración se aplica a los seres humanos: tampoco en nuestro caso tenemos buenos motivos para sostener que hay algo más que mera intencionalidad derivada. De hecho, el experimento que aquí hemos presentado de forma muy resumida puede ser entendido como una versión con variaciones de la propuesta de Dawkins (1976) de entender a los seres humanos como máquinas de supervivencia que fueron diseñadas para perpetuar la existencia de sus genes egoístas.

La idea de fondo que sustenta tanto este experimento mental como la posición de Dennett respecto de este tema es que si nos tomamos en serio la teoría de la evolución darwiniana debemos asumir que no somos más que el resultado de un proceso histórico que nos fue moldeando de modo tal que nuestros mecanismos de entrada y salida de información fueron adquiriendo cada vez mayor complejidad, sin existir, por ende, un límite o instancia precisa en el que podamos decir algo como "aquí es donde milagrosamente aparece la mente". En síntesis, para Dennett nuestro complejo equipamiento cognitivo es el resultado de un proceso de diseño llevado a cabo por la evolución por selección natural. Esto lo lleva a sostener que "si ha de haber alguna intencionalidad original —original sólo en el sentido de no derivar de ninguna otra fuente ulterior - la intencionalidad de la selección natural se merece el honor" (Dennett 1998, p.281).

Esta noción acerca de la intencionalidad subyace en el corazón de su teoría de los sistemas intencionales, según la cual tener una creencia no es más ni nada menos que ser un sistema intencional cuyo comportamiento resulta mejor explicado y predicho si se le atribuye dicha creencia. Esta teoría está expuesta en La actitud Intencional (1998) donde propone distinguir entre tres actitudes [stances]: la actitud física, la del diseño y la intencional. Se trata de estrategias de razonamiento que nos permiten hacer predicciones acerca de los sistemas que estamos interpretando, aunque deben ser pensadas más como destrezas que como operaciones intelectuales. Según la teoría de los sistemas intencionales, para adoptar la actitud física es necesario tratar al sistema cuyo "comportamiento" se quiere predecir en función de su constitución física y utilizar los conocimientos - científicos y/o folk- que tenemos acerca de cómo se comportan los objetos macroscópicos para realizar las predicciones. La actitud del diseño en muchos casos resulta más eficiente para realizar interpretaciones, dado que no exige un conocimiento de la constitución física de un sistema, sino que apoya su predicción en la suposición de que este está diseñado para comportarse de cierta forma en distintas circunstancias. Se trata, entonces, de una actitud interpretativa que consiste en tratar al sistema cuyo "comportamiento" se quiere predecir bajo el supuesto de que sus partes cumplen funciones que obedecen a un diseño satisfactorio. Por último, la actitud intencional es una estrategia que consiste en tratar al sistema cuyo comportamiento se quiere predecir como un agente racional con creencias, deseos 
y otros estados mentales dotados de intencionalidad. Como se señaló anteriormente, esta teoría entiende que tener una creencia $p$ no es nada más ni nada menos que ser un sistema intencional cuyo comportamiento resulta mejor explicado y predicho si se le atribuye dicha creencia. En palabras de Clark, la actitud intencional dennettiana implica que "humanos, perros, insectos e incluso meros termostatos son todos capaces de creer y desear, fundamentalmente, en el mismo sentido teórico" (Clark 2002, p.187).

Esta concepción acerca de los estados mentales guarda relación con la tesis elaborada por Quine (1969) acerca de la indeterminación de la traducción radical. Para exponer este vínculo, es necesario señalar cuál es el estatus ontológico que la teoría dennettiana confiere a los estados mentales. Esta teoría sostiene que la postulación de las creencias depende de la adopción de una perspectiva interpretativa, que, como explicamos con anterioridad, recibe el nombre de actitud intencional. Dicha dependencia de la interpretación confiere un componente "anti-realista" a su teoría de los estados mentales. Sin embargo, esta demarcación de las versiones fuertes del realismo de los estados mentales, tampoco llevan a Dennett sostener un "instrumentalismo" o "interpretativismo" extremos. A diferencia de estas posturas, para Dennett el éxito o fracaso de una atribución intencional es un hecho perfectamente objetivo. En ese sentido, según su teoría, las creencias, deseos e intenciones son algo que habita objetivamente el mundo en el que vivimos, como también lo hacen otras abstracciones, como, por ejemplo, el centro de gravedad de un objeto. En rigor, en un artículo que intenta precisar estos matices acerca de los compromisos ontológicos de su propuesta, Dennett (1991) afirma que su teoría podría ser clasificada como una variante de "realismo moderado". ${ }^{5}$ En síntesis, esta teoría sostiene que cuando se atribuye un estado mental, no hay detrás un hecho profundo que determina aquello acerca de lo que realmente es. Existen hechos que determinan los contenidos de los estados mentales, pero son muchos hechos y, además, se entiende que los contenidos de los mismos pueden ser, en algún punto de la interpretación, "simplemente indeterminados" (Dennett 1998, p.276).

La perspectiva de Dennett sobre la naturaleza de lo mental, que hemos designado como 'perspectiva de la intencionalidad derivada', se distingue sustancialmente de lo que entendemos como una perspectiva cartesiana de lo mental. Al emplear el término 'perspectiva cartesiana', no nos referimos a tesis o ideas expuestas por el propio Descartes, sino, como es usual en la literatura sobre estos temas, a un modelo del que pueden derivarse o inferirse otras tesis que resultan compatibles con él. En el corazón de dicho modelo se encuentra la tesis de que la intencionalidad original de las mentes humanas es de un carácter diferente a la de los productos que derivan su intencionalidad de aquellas. ${ }^{6}$ Vamos a argumentar que esta perspectiva cartesiana parece estar presente, de forma explícita o implícita, en los fundamentos de las discusiones acerca del significado de las obras de arte. 


\section{Las discusiones acerca del intencionalismo}

En el primer apartado de este artículo defendimos, por medio del experimento mental del gato montajista, que cada interpretación de una obra de arte se encuentra parcialmente determinada por el hecho de que esta fue producida por la acción intencional de sus creadores. Así, según esta conclusión parcial, el significado de un documental observacional es diferente del que tendría un registro similar que no haya sido producido por nadie. Utilizando los términos expuestos en la sección anterior, se puede decir que, aunque ambos objetos (el documental real y el resultado azaroso que se relataba en el experimento mental) exhibirán intencionalidad de modo derivado, el hecho de que uno de ellos deba su contenido a las intenciones de una mente parece incidir en su significado. Esta sentencia comparte algunos rasgos con la postura intencionalista en hermenéutica, esto es, aquella que sostiene que el sentido de un texto está dado por las intenciones que tuvo su autor a la hora de producirlo. Dicha postura ha sido rebatida y reformulada desde mediados del siglo pasado a esta parte. En este apartado vamos a exponer la teoría intencionalista del sentido de las obras de arte, la crítica que ha recibido por parte de Wimsatt \& Beardsley (1946) bajo el nombre de falacia intencional y algunas teorías intencionalistas recientes más sofisticadas.

La perspectiva intencionalista en hermenéutica sostiene que el verdadero sentido de un texto se encuentra en la intención que tenía el autor en el momento de su producción. Siguiendo a Michael Wreen (2014) la cuestión que está en juego en el debate sobre el intencionalismo es cuál es el vínculo entre las afirmaciones (1) y (2):

(1) El artista quiso que $\mathrm{X}$ significara $\mathrm{P}$ en la obra $\mathrm{O}$

(2) $\mathrm{X}$ significa $\mathrm{P}$ en la obra $\mathrm{O}$

De acuerdo con el intencionalismo, (1) implica (2), dado que el significado de X simplemente es lo que el autor quiso decir con X. Esta perspectiva es la que predominaba, generalmente de forma implícita, en el campo de la crítica literaria de la primera mitad del siglo XX. En palabras de Wimsatt \& Beardsley (1946): "difícilmente haya un problema de la crítica literaria en el que el enfoque del crítico no sea juzgado por su visión sobre las intenciones" (p.468). Si bien el intencionalismo fue fuertemente criticado a mediados de ese siglo, se han propuesto defensas posteriores a ese momento de enjuiciamiento. Hirsch, un destacado crítico literario norteamericano, es un buen representante de esta corriente, dado que en algunas publicaciones (1967a, 1967b) ha defendido la perspectiva de que un texto significa lo que su autor quiso decir mediante él; es decir, que (1) implica (2). Hirsch contrapone la propuesta intencionalista con la tesis de la autonomía semántica del lenguaje, esto es, la idea de que las secuencias de palabras tienen un sentido preciso con independencia del mundo 
subjetivo. Su argumento central consiste en sostener que, dado que toda secuencia de palabras tiene muchos significados posibles, el único criterio legítimo para poder precisar cuál es el significado determinado de un texto es recurrir a las intenciones del autor (especialmente en Hirsch 1967b). Las alternativas a esta elección son, para este pensador, formas encubiertas de realizar la misma operación para elegir entre los posibles significados, privilegiando la interpretación de un agente menos legítimo para esta tarea que el autor, a saber, el crítico. Un punto que Hirsch considera incuestionable es que el sentido de un texto, para poder ser compartido, tiene que ser determinado. Dado que el único modo de establecer el verdadero sentido de un texto, entre una variedad de posibles interpretaciones, es recurriendo a las intenciones del autor, el texto deja de ser entendido como una porción del lenguaje, caso en el que se lo entendería como un objeto puramente público y pasa, en cambio, a ser entendido como un fenómeno que representa el significado verbal en tanto está determinado por las intenciones y objetivos de un autor. El significado, para Hirsch es "una cuestión de consciencia, no de palabras" (Hirsch 1976b, p.13).

El texto bisagra en el que queda condensada la ola crítica a la perspectiva intencionalista es el artículo "La falacia intencional" de Wimsatt \& Beardsley (1946), donde se intenta demostrar que no es posible ni deseable acceder a las intenciones de los autores para interpretar sus producciones artísticas. La crítica apunta contra la concepción neo-romántica según la cual el ideal de belleza es comprendido como una buena conjunción entre la intuición del autor y la expresión que consigue, mientras que, el de fealdad, es pensado como la frustración de la realización de esas intenciones. Desde esa perspectiva romántica, el hecho artístico formaría parte de la esfera privada y la tarea del crítico sería determinar la intención del autor. La fórmula intencionalista, según la reconstrucción de Wimsatt \& Beardsley es que "Para juzgar el desempeño del poeta, debemos saber qué pretendía” (p.468-9). Según estos autores, el que la causa de la existencia de un poema radique en haber sido diseñado y ejecutado por un autor, no implica que ese diseño sea necesariamente el parámetro para juzgarlo. Antes bien, el diseño o la intención del autor no está disponible ni es deseable como un estándar para juzgar el éxito de una obra de arte.

Para defender dicha postura, uno de sus principales argumentos radica en la inaccesibilidad: si la tarea del crítico fuera juzgar al poema en función de las intenciones que tenía el autor a la hora de realizarlo, aquel debería, en primer lugar, conocerlas. ¿Cómo puede un crítico conocerlas? Si el poema es exitoso, es el poema mismo el que muestra qué es lo que el autor intentaba hacer, por lo que la apelación a las intenciones con las que fue realizado se vuelve, en algún sentido, prescindible. Y, si el poema fracasó respecto a las intenciones que tenía su autor, no es buena evidencia de lo que pretendía, por lo que el crítico debería ir a buscar afuera del poema información sobre esto. Según Wimsatt \& Beardsley, ni siquiera los mismos intencionalistas estarían dispuestos a defender que esto último fuera deseable. ${ }^{7}$ Por otro lado, dado que, con 
mucha frecuencia, podemos interpretar correctamente una obra de arte con poco o ningún conocimiento del artista, la postura intencionalista debe ser incorrecta.

Existen muchos debates y pocos acuerdos respecto de cuál es el alcance de lo que se argumenta efectivamente en el famoso artículo de Wimsatt \& Beardsley. Hay quienes interpretan que el ataque que se proponía en contra de "La falacia intencional" era mucho menos ambicioso. Por ejemplo, Farrell (2017) sostiene que los argumentos presentados en el artículo apoyan la "sensata" postura de que los autores son responsables de los diseños de sus poemas y que las intenciones, cuando son exitosas, están en los poemas mismos en un sentido que pueden ser desentrañadas por los buenos lectores (cfr. Farrell 2017, p.41).

Aunque una exégesis pormenorizada de "La falacia intencional" excedería ampliamente los objetivos de este trabajo, resulta relevante, en cambio, examinar su recepción tanto en la filosofía como en la teoría literaria. En estos ámbitos se lo ha interpretado más bien como un ataque contundente a la idea de que el significado de los textos está dado por las intenciones de los autores. Resulta ilustrativa, en relación con este punto, la afirmación con la que un exponente más reciente del intencionalismo, como Hirsch, introduce su artículo "En defensa del autor": "Es una tarea para la historia de la cultura explicar por qué ha habido en las pasadas cuatro décadas un ataque pesado, y en buena medida victorioso a la sensata creencia de que un texto significa lo que su autor quiso decir." (Hirsch 1967b, p.11, nuestra traducción.)

La posición anti-intencionalista que se atribuye a Wimsatt \& Beardsley se consideró por mucho tiempo como la posición dominante, aunque en un relevamiento de la bibliografía más reciente podemos encontrar defensores de distintas formas de intencionalismo. Una de sus versiones más sofisticadas recibe el nombre de 'intencionalismo modesto de las intenciones efectivas' (IMIE) [modest actual intentionalism], propuesto por Carroll $(1997,2000)$. La aclaración de que su postura es acerca de intenciones reales o efectivas tiene que ver con que también han surgido propuestas sobre lo que el autor llama un 'intencionalismo hipotético' (IH). Ahora bien, el IMIE sostiene que la interpretación correcta es la que es compatible con las intenciones del autor, siempre y cuando las mismas se vean plasmadas en la obra. Esta segunda condición distinguiría al IMIE de versiones más radicales de intencionalismo. Carroll acepta que las unidades lingüísticas o literarias pueden apoyar más de un significado. Frente a este hecho, su postura afirma que algunos de los significados que se ven respaldados por la obra son falsos y que los únicos adecuados serán aquellos que coincidan con las intenciones que efectivamente tenía el autor o los autores en el momento de la producción de la obra.

Según Gaut (2010), el intencionalismo, en sus distintas variantes, se enfrenta a dos desafíos: por un lado, dar cuenta de que nuestras intenciones a veces fracasan $y$, por otro, de que muchas veces hay accidentes felices que efectivamente integran el significado de la obra, aunque no puedan ser atribuidos a las intenciones del au- 
tor (cfr. p.155-6). El primero de ellos está fuertemente vinculado con una de las principales críticas que se realizan al intencionalismo bajo el nombre de "HumptyDumptysmo"8, e.e., una perspectiva según la cual una obra posee el significado que unilateralmente le asigna su propio autor, independientemente de si pudieran atribuírsele otros significados, convencionalmente aceptados, por parte de los intérpretes. El desafío de las intenciones fallidas no constituye un problema para Carroll, dado que su postura es "modesta" en la medida en que solo toma en cuenta las intenciones que de hecho se ven respaldadas por la obra. En cambio, su teoría no puede responder al segundo desafío, dado que, desde esta perspectiva, para que una obra tenga determinado sentido, el mismo tiene que haber formado parte de los planes intencionales del artífice. Por otra parte, esta versión sofisticada de intencionalismo también ha sido criticada por las implicancias que tiene para la crítica literaria; así, se dice que la misma fomenta que el intérprete se aleje del texto. También se dice que esta postura está comprometida con la "falacia de parafrasear" (Carroll 2000), según la cual la tarea del crítico estaría limitada a decir lo que el autor quiso decir." Dejaremos de lado la discusión de grano fino respecto de estas implicancias, dado que pretendemos defender una perspectiva que se diferencia de estas posturas en virtud de sus fundamentos teóricos.

El $I H$, propuesto inicialmente por Tolhurst (1979) y defendido después por Currie (1995) y Levinson (1996), sostiene que lo que determina el significado de un texto literario no son las intenciones reales o efectivas del autor, sino más bien las intenciones que podemos atribuir a un autor hipotético. En la formulación de Levinson, se trataría de las intenciones que son óptimamente hipotetizadas por una audiencia deliberada, estando disponibles todos los recursos relevantes en la estructura interna de la obra y en el contexto que la rodea. El corazón del significado de la enunciación puede ser concebido analíticamente como nuestra mejor proyección, apropiadamente informada, acerca del significado que el autor quería comunicar, desde nuestra posición de intérpretes deliberados [intended] (Levinson 1996). Levinson considera que hay una diferencia radical entre las interpretaciones que hacemos de los comportamientos o las expresiones cotidianas de las personas (en los que, si hay ambigüedad, estamos dispuestos rápidamente a sustituir lo que se dijo por la aclaración que hace el agente de cuáles eran sus intenciones) y lo que ocurre con las obras de arte, donde nos importa más bien la obra misma. A su vez, sostiene que se trata de la mejor interpretación en un sentido dual: epistemológica y artísticamente. Principalmente, es la mejor interpretación en términos epistemológicos, en el sentido de que tiene más probabilidades de ser correcta cuando se dispone de toda la evidencia relevante para un lector ideal. En segundo lugar, la mejor atribución de intenciones a un autor hipotético es la que vuelve a la obra en cuestión artísticamente más interesante.

El primer desafío de Gaut, referido a que los autores pueden fracasar en sus propósitos, es respondido fácilmente por esta perspectiva, dado que las intenciones que 
puede haber tenido el autor y no se ven plasmadas en la obra, nunca serán hipotetizadas por la audiencia. El segundo resulta un poco más problemático, dado que algunos de estos accidentes ("ecos" o repercusiones inesperadas, significados no previstos) podrán ser pensados como intenciones del autor hipotético, pero hay otros que no lo son, que se muestran como hallazgos imprevisibles. ${ }^{10}$ Incluso reconociendo esta distinción, un defensor del $I H$ podría argüir que, en todas las obras que no son improvisaciones, podemos atribuir al autor hipotético la decisión que llevó a ese resultado no planificado (ya sea porque diseñó el dispositivo que "capturó" el accidente, ya sea porque decidió incorporar el resultado en un momento de montaje, edición o curaduría). Sin embargo, quizá también se puede pensar que hay accidentes felices que no pueden ser atribuidos a la voluntad del autor en ningún momento del proceso de elaboración de la obra, dado que se trata, por ejemplo, de "ecos" o repercusiones inesperadas que emergieron meses después de la publicación o exhibición pública de la misma y que tienen que ver con un hecho histórico que no se podía prever en el momento de su producción. ${ }^{11}$ Levinson (1996) dedica gran parte de su artículo a mostrar cómo el $I H$ podría responder de manera satisfactoria a esta objeción, aunque no se comprometa con ninguna de estas formas en particular y muchas de ellas impliquen hacer algunos agregados a su propuesta. Sin embargo, en términos generales, esta corriente no parece resolver de forma satisfactoria el desafío de explicar el aporte al significado que pueden realizar los llamados accidentes felices. De cualquier modo, este no es el motivo por el cual consideramos que la teoría intencionalista es inadecuada. Antes bien, creemos que es necesario discutir algunos de sus fundamentos.

\section{La perspectiva de la intencionalidad derivada y el intencionalismo}

En este apartado pretendemos mostrar por qué las distintas versiones de intencionalismo presentadas son incompatibles con la perspectiva de la intencionalidad deriva$d a$. Esto podría entenderse como un resultado esperable, dado que el mismo Dennett (1990) señala que el intencionalismo criticado por Wimsatt \& Beardsley es erróneo. Sin embargo, también pretendemos señalar que la perspectiva dennettiana de la intencionalidad no es incompatible con todo tipo de intencionalismo.

En lugar de realizar un análisis pormenorizado de cada una de las teorías intencionalistas, nos gustaría poner en discusión algunos de sus supuestos. En particular, consideramos que tanto el IMIE como el IH dependen de una concepción cartesiana de lo mental, dado que defienden una distinción tajante entre intenciones efectivas e intenciones hipotéticas. En ese sentido, pretendemos hacer una evaluación de dicha perspectiva, para sentar las bases de una posición alternativa, que sea consecuente 
con la perspectiva de la intencionalidad derivada. Al trasladar el debate al ámbito de la filosofía de la mente, podríamos decir que nos estamos haciendo cargo de un diagnóstico realizado por Colin Lyas citado en el epígrafe de este artículo, según el cual la disputa en estética sobre la relevancia de las referencias a las mentes e intenciones de los artistas ha sido tan difícil de tratar porque la misma descansa en problemas de filosofía de la mente que son igualmente difíciles de tratar (cfr: Lyas 1992, p.137).

Tanto el IH como el IMIE señalan (el primero como virtud, el segundo como defecto) que postular intenciones hipotéticas haría que la interpretación de las obras de arte sea distinta a la interpretación en contextos comunicativos ordinarios, pues, en estos últimos nos interesan las intenciones reales. Pongamos el caso de una interacción en la vida cotidiana en la que un agente realiza una acción que es interpretada de cierto modo por un interlocutor y, luego, expresa que sus intenciones eran diferentes de aquellas que su interlocutor le atribuyó. Ambas versiones del intencionalismo estarían de acuerdo en que, dada esa situación, el interlocutor debería modificar su interpretación, para adecuarla a aquello que el agente declara. Según el IMIE, de algún modo, hacemos lo mismo con las obras de arte. Para el $I H$, en cambio, nos comportamos de otra forma frente a las obras de arte. Ahora bien, ambas posiciones parecen asentarse sobre un par de supuestos que ocupan un lugar central en la concepción cartesiana de lo mental: que los estados mentales existen con independencia de los comportamientos que puedan causar. La concepción que sustenta estos supuestos entiende que, mientras que los comportamientos son eventos públicos, los estados mentales son de carácter privado y, por lo tanto, pueden ser conocidos por la vía de acceso privilegiada que es el conocimiento introspectivo. Este tipo de conocimiento se manifiesta en los reportes verbales (sinceros), los enunciados psicológicos en primera persona. De acuerdo a este enfoque, sería sensato pensar que, si alguien declara con honestidad que un acto determinado fue realizado con ciertas intenciones, aunque las mismas vayan en contra de lo que nos parece razonable inferir a partir de la evidencia comportamental, debemos cambiar nuestra interpretación acerca de sus propósitos.

Ahora bien, desde una perspectiva que podríamos considerar anti-cartesiana, los estados mentales son, justamente, aquello que postulamos para explicar y predecir los comportamientos. Y dado que las expresiones lingüísticas son sólo un componente del comportamiento total de los agentes, desde una concepción de lo mental más cercana a la de Dennett podríamos sugerir que, si las mismas estuvieran en contradicción con el conjunto de su comportamiento no lingüístico, nuestra interpretación iría en una dirección contraria a la de estas declaraciones. En otros términos, desde la perspectiva de la intencionalidad derivada las intenciones del agente son entendidas como aquello que se puede inferir del conjunto total de su comportamiento y no como algo que puede estar en completa oposición a sus acciones. Desde esta visión, la diferencia entre las intenciones hipotetizables y las intenciones efectivas tiene lí- 
mites borrosos, dado que los estados mentales tienen, en última instancia, el mismo grado de realidad que la mejor hipótesis que alguien podría construir para interpretar el comportamiento de un agente, siempre y cuando estén a su disposición todos los elementos epistémicamente relevantes.

Antes de proceder a reconstruir algunos aspectos positivos que debería mantener una teoría del sentido de las obras de arte consecuente con una perspectiva de la intencionalidad derivada, es pertinente señalar que el mismo Dennett (1990) ha sostenido que los supuestos que sustentan al intencionalismo criticado por Wimsatt \& Beardsley son, no sólo falaces por su falta de asidero en la crítica artística, sino, además, dependientes de una concepción de lo mental que es objetable. Al respecto, pretendemos señalar que este argumento no debe ser leído como una crítica contundente a toda forma de intencionalismo.

En "The interpretation of Texts, People and Other Artifacts", Dennett (1990) reconstruye la intuición de que habría en la mente del autor algún hecho profundo o característica que determinaría el sentido de la obra, incluso aunque nadie pueda tener acceso al mismo. Wimsatt \& Beardsley (1949) habrían demostrado la irrelevancia de tal intención a la hora de determinar el sentido del texto. Dennett añade a ello que, desde una concepción adecuada de lo mental, ya ni siquiera estamos autorizados a sostener que tales fenómenos existen, en sentido estricto. El esquema del argumento se puede reconstruir de la siguiente manera:

Las perspectivas intencionalistas implican (1):

(1) El sentido del texto depende de hechos profundos que ocurren en la mente del autor en el momento de la creación.

La crítica de Wimsatt \& Beardsley (1949) consiste en (2):

(2) Los hechos profundos a los que apela (1) son irrelevantes para el sentido del texto, dado que este es un objeto autónomo.

El argumento de Dennett que radicaliza la crítica al intencionalismo consiste en (3):

(3) Los hechos profundos a los que apela (1) no existen, dada la teoría de los sistemas intencionales y, más específicamente, la tesis de que toda intencionalidad es derivada.

Con lo cual, el crítico del intencionalismo debería reforzar su posición. (3) constituye una crítica de (1) más radical que (2). (3) y (2) se complementan en la idea central de los textos (u obras) son objetos autónomos.

Ahora bien, nos gustaría señalar que si bien el argumento de Dennett socava las bases de una perspectiva intencionalista que entienda que los contenidos de las intenciones del artista están determinados en virtud de hechos profundos, su concepción 
acerca de los estados mentales no tendría por qué ser incompatible con toda forma de intencionalismo. Como se expuso en el segundo apartado, Dennett sostiene una teoría de lo mental según la cual no es necesario postular hechos profundos que determinen los contenidos de los estados mentales. Sin embargo, se podría alegar que no toda perspectiva intencionalista está comprometida con (1), es decir, que podría haber un intencionalismo que no entienda a las intenciones como hechos profundos ocurriendo en la mente de los autores. De hecho, el anti-realismo de los estados mentales de Dennett sostiene que no hay hechos profundos "en la cabeza", pero, al mismo tiempo, propone seguir hablando de creencias y deseos y, por ende, también de intenciones. Así, nada impide que se pueda defender un realismo moderado a lo Dennett y, al mismo tiempo, estar en el bando de los intencionalistas hermenéuticos. Esto es así porque, según la perspectiva dennettiana de lo mental, es posible seguir hablando de agentes intencionales y, por ende, sigue siendo posible atribuir intenciones a los autores de las obras. Esto nos permitiría sostener nuevas maneras de entender el intencionalismo, que no conciban a las intenciones (ni a los estados mentales, en general) como fenómenos determinados en virtud de hechos profundos en la mente de los agentes.

\section{La interpretación de las obras de arte desde la perspectiva de la intencionalidad derivada}

Ahora bien, nótese que hay muchos aspectos de las concepciones del significado de las obras de arte presentes en la discusión acerca del intencionalismo que son dependientes del viejo esquema cartesiano y que la perspectiva de la intencionalidad derivada nos obligaría a abandonar. La crítica que Dennett realiza a la concepción clásica de los contenidos mentales plantea un cambio en nuestra concepción de la naturaleza de la intencionalidad en general; cambio que influye en nuestra concepción de objetos intencionales como las obras de arte. Desde la perspectiva dennettiana, toda intencionalidad es, en definitiva, derivada de algo no intencional, perdiendo así los límites claros que antes caracterizaban a la intencionalidad original y que eran heredados por la derivada.

En primer lugar, en términos ontológicos, según la perspectiva cartesiana, toda obra creada por seres humanos posee intencionalidad en virtud de haberla recibido de una intencionalidad original (mental) que es de carácter intrínseco; es decir, que le corresponde a un fenómeno en virtud de su naturaleza y no en virtud de sus relaciones con otros fenómenos. Si así fuera, el sentido de la obra quedaría restringido a los contenidos de la intencionalidad intrínseca que le dieron origen. Por este motivo, dicho sentido poseería un carácter objetivo, siendo independiente de las posibles interpretaciones que puedan hacerse de la obra. Incluso si el sentido que quiso darle el 
autor resultara incomprensible para cualquier intérprete, actual o posible, el mismo se mantendría intacto.

Ahora bien, si pensamos, como Dennett, que toda intencionalidad es derivada, habría que renunciar tanto a la idea de objetividad de los significados de la obra de arte, como a la de que el significado es algo preciso y determinado, y admitir que siempre puede haber un grado inextinguible de indeterminación. Así, es necesario abandonar la idea de que existe algo que el texto realmente significa. A esto se suma que los significados no estarán dados de una vez y para siempre en el momento de la creación, como si el origen fuera un momento fundacional que marca la naturaleza última de las cosas de modo permanente.

En términos propositivos, podemos decir que los significados serán el resultado de procesos interpretativos, por lo que resultarán siempre dependientes de la posibilidad de una atribución. Esto no implica que debamos sostener un relativismo del significado, dado que hay interpretaciones que serán, objetivamente hablando, más adecuadas que otras; pero sí será preciso renunciar a la idea de que el significado es algo ontológicamente "previo" e independiente de la interpretación, algo que una obra podría poseer aun cuando no fuera interpretable en principio. En cuanto a la forma de decidir entre interpretaciones rivales de una misma obra de arte, no dependería de la correspondencia entre los significados atribuidos y ciertos hechos profundos en la mente del autor, que podrían resultar inaccesibles a cualquier intérprete, sino de cómo se vinculan dichas interpretaciones con los elementos públicamente disponibles, presentes en la obra misma y en sus contextos de presentación. Evidentemente, dentro de ese contexto de presentación podría incluirse una declaración del autor explicando cuáles fueron sus propósitos e intenciones. La propuesta que estamos presentando no implica que el testimonio del autor deba ser desestimado, pero sí que será tomado como un elemento más entre otros.

En sintonía con el primer aspecto, también se abandona la búsqueda del significado unívoco de una obra de arte y se admite la posibilidad de que exista un grado de indeterminación del significado. Nuevamente, esto no supone negar que hay interpretaciones mejores que otras, sino que es posible que haya un aspecto parcial en el que dos interpretaciones atribuyen significados incompatibles entre sí y resulte imposible decidir cuál de las dos está en lo cierto. En una situación de ese tipo, la perspectiva que estamos presentando se opone a la idea de que la obra en cuestión tiene, en ese aspecto puntual, un significado u otro y que el mismo resulta difícil o imposible de establecer de manera determinada. Antes bien, sostiene que, respecto de ese aspecto, el significado es simplemente indeterminado.

Por último, desde la perspectiva de la intencionalidad derivada no se debería pensar que toda interpretación posible está restringida a su origen. Podríamos sugerir dos sentidos diferentes de la palabra "origen". Uno que no es de orden temporal, sino metafísico, dado que hace referencia a qué clase de propiedades poseían las enti- 
dades que crearon algo asumiendo que las mismas se transfieren de algún modo a lo creado. En ese sentido, una teoría como la que estamos formulando deja de lado una consideración sobre los orígenes. Sin embargo, hay otro sentido del término que sí es temporal y hace referencia a la génesis histórica. En cuanto a este origen histórico, hay ciertas consideraciones relativas a sus causas y a los contextos de creación, que pueden enriquecer nuestra concepción de una obra de arte, sin por eso reducir el significado de la misma a esa búsqueda del significado originario, como si el significado estuviera fijado desde el inicio, en el acto de la creación (Ver Tabla 1).

Tabla 1: Aspectos del significado en la obra de arte

\begin{tabular}{|c|c|}
\hline Perspectiva cartesiana de lo mental & Perspectiva de la intencionalidad derivada \\
\hline Objetivo & Relativo a una atribución \\
\hline Determinado & Parcialmente indeterminado \\
\hline Vinculado a su origen & Vinculado a su génesis histórica \\
\hline
\end{tabular}

Desde esta visión, el significado de una obra de arte depende de interpretaciones. Sin embargo, a diferencia de las consideraciones hermenéuticas clásicas que discutían cuál es el aspecto nodal en el cual debía basarse para realizar la interpretación (por ejemplo: las intenciones del autor real, las intenciones del autor hipotético, etc.), la perspectiva de la intencionalidad derivada considera que no hay un único aspecto determinante. En cambio, se trata de una perspectiva pluralista del significado que entiende que hay muchos elementos potencialmente relevantes para la interpretación. Sin embargo, como ya lo anticipamos, las interpretaciones no son completamente libres, sino que están parcialmente constreñidas por la obra misma.

Nuestra propuesta es que las atribuciones o interpretaciones que constituyen el significado de la obra se realizan a distintos niveles. Seguramente, uno de ellos contiene interpretaciones que surgen a partir de experiencias ligadas a la percepción de la obra en su dimensión estética más inmediata. Creemos que este nivel podría incluir una consideración de las características observables más generales (colores, ritmos, tonalidades, formas, etc.), pero también aquellas interpretaciones que se despiertan a partir de la captación de regularidades. Como señalan Bullot \& Reber (2013) existen numerosos estudios que muestran que espectadores desconocedores de las corrientes artísticas que dieron lugar a las obras y de sus correspondientes marcas de estilo son capaces, sin embargo, de reconocer estas últimas a partir de una identificación de patrones estéticos presentes en las obras. Así, por ejemplo, Machotka (1966) y Gardner (1970) muestran que los niños más pequeños clasifican pinturas en virtud del contenido, mientras que los niños mayores lo hacen en virtud del estilo, incluso si no han tenido ninguna formación o exposición anterior a obras de ese tipo. En segundo lugar, parece sensato sugerir que la interpretación de las narraciones (o acciones 
aisladas) representadas en algunas obras de arte, deben ser interpretadas primordialmente desde otro nivel de análisis. En este nivel están involucradas habilidades que utilizamos en la interacción cotidiana y que forman parte de nuestra cognición social, como la capacidad de simular estar en la situación de otro agente y la capacidad de realizar predicciones utilizando nuestra psicología de sentido común.

Ahora bien, queremos sostener que, además, existe un nivel de análisis particular característico de la interpretación de las obras de arte, que funciona en una especie de nivel "meta-narrativo" y que nos situamos en él cuando asumimos que esto fue realizado por alguien que quería expresar algo. Reconocer la existencia de este nivel interpretativo nos permite dar cuenta de un rasgo de las interpretaciones de las obras de arte que han capturado distintas versiones del intencionalismo: aquel que señala que parte del sentido de la obra se deriva del hecho de que la misma fue producida por un agente con intenciones. Así, aunque sostenemos que el intencionalismo es erróneo en sus distintas versiones, consideramos que un aspecto fundamental del significado de las obras de arte emerge sólo cuando tenemos en cuenta que fueron realizadas por sus autores con determinadas intenciones, y, en consecuencia, que no estamos ante un producto accidental. La importancia de este nivel interpretativo es la que quisimos evidenciar con el experimento mental del gato montajista. En él se sugiere que parte de las interpretaciones que despierta Austerlitz son subsidiarias del hecho de que los intérpretes suponen un autor detrás de la obra, y no meramente un mecanismo del tipo del ejemplificado con la propuesta de la cámara de seguridad y el gato.

Recapitulando: hasta aquí hemos defendido que, si se adopta la perspectiva de Dennett acerca de la intencionalidad, no es posible sostener que existen hechos profundos en la mente de los autores de una obra de arte que determinan el sentido de sus creaciones. Además, siguiendo a Wimsatt \& Beardsley hemos sostenido que la apelación a los estados mentales de los creadores es no sólo imposible sino además irrelevante para determinar el sentido de una obra. En sintonía con ello, propusimos un cambio en la concepción del sentido de las obras de arte, que se propone entenderlo como algo relativo a una atribución, de carácter parcialmente indeterminado y como poseyendo una historia más que un origen fundacional. Ahora bien, ¿cómo puede ser esta perspectiva compatible con la intuición de que parte del sentido de una obra de arte está vinculado al hecho de que asumimos que hay un creador detrás? Sugiriendo que, para interpretar una obra de arte es preciso adoptar una estrategia interpretativa del tipo de las tres actitudes o enfoques propuestos originariamente por Dennett (1998) — la actitud física, la del diseño y la intencional-. Sostenemos que una parte esencial del sentido de una obra de arte emerge cuando adoptamos lo que denominaremos la actitud de la obra de arte, que debe ser entendida como un subtipo de la actitud intencional. Esta estrategia interpretativa consistiría en abordar determinados objetos suponiendo que un agente los creó intencionadamente, con el 
objetivo de transmitir algo. La actitud de la obra de arte guarda algunas semejanzas con las propuestas de Bullot \& Reber (2013) de la actitud del diseño artístico [artistic design stance] y la propuesta de Linson (2013) de la actitud expresiva. Sin embargo, no se identifica con ninguna de ellas. En el siguiente apartado explicaremos en qué consiste, cuáles son algunas de sus implicancias y qué vínculo mantiene con sus propuestas hermanas.

Ahora bien, antes de pasar a la siguiente sección, es relevante señalar que la perspectiva que resultó de nuestro análisis guarda similitudes con conclusiones obtenidas en el campo de la filosofía del arte. Por ello, señalaremos de manera muy sucinta que nuestra propuesta comparte algunos rasgos con concepciones estéticas como las de Nelson Goodman y Arthur Danto y, más en general, con perspectivas constructivistas.

Nelson Goodman (1976, 1990 [1978]) señala que las obras de arte son símbolos que clasifican partes de la realidad. Así, los estilos artísticos que perduran en el tiempo, lo que se entiende como literal o como metafórico, lo que se entiende como conservador o como revolucionario, depende en gran medida de las concepciones que están arraigadas en una comunidad en un periodo determinado. A su vez, según Goodman (1990 [1978]), las "doctrinas puristas" que llaman a dejar de lado los elementos externos o extrínsecos a las obras de arte - muchas veces vinculados con su carácter "simbólico", en el sentido de representar algo metafóricamente, o simplemente representarlo- están acertadas y equivocadas al mismo tiempo. Están en lo cierto en la medida en que lo que debería cobrar mayor relevancia es la obra misma, no las cosas externas a ella - y aquí debemos incluir tanto a los fenómenos representados, como al autor de la obra y las intenciones que tenía al realizar su trabajo-. Pero, por otra parte, las "doctrinas puristas" se equivocan al asumir que el carácter simbólico se agota en la representación y que todos los símbolos simbolizan cosas que están fuera de ellos mismos; asunciones que implican la errónea idea de que puede haber arte sin símbolos. Para Goodman, la obra es un tipo especial de símbolo, dado que se trata de un símbolo que ejemplifica las propiedades que simboliza (Goodman 1987 [1990], cfr. 101). Así, la primacía de una obra con respecto a aquello a lo que ella refiere no implica la negación o la no consideración de sus funciones simbólicas, sino que, por el contrario, se deriva de las características de la obra en tanto símbolo.

A grandes rasgos, la visión de Goodman guarda similitudes con la propuesta que elaboramos en este artículo. De acuerdo con su teoría, la obra no es nunca simplemente el resultado del genio del artista. Antes bien, en tanto símbolo, su sentido se construye en la interpretación y depende en gran medida del modo en el que la misma es presentada y del modo en el que se relaciona con los otros símbolos que la rodean. Adicionalmente, esta perspectiva también sostiene que la actitud interpretativa de los espectadores es esencial y que una obra siempre estará sujeta a diferentes interpretaciones; lo que se encuentra en concordancia con nuestra propuesta de que siempre habrá un grado inextinguible de indeterminación. 
Por su parte, para Danto $(1964,1981)$ una obra de arte, para serlo, requiere un contexto que la sitúe como tal: debe pertenecer al mundo del arte. El concepto mundo del arte cumple, por un lado, una función ontológica, dado que permite fijar la identidad artística de un objeto. Por otro lado, cumple un rol epistemológico, dado que permite identificar cuáles son las obras de arte y qué tipo de constreñimientos hay que tener en cuenta a la hora de interpretarlas en cada caso. Por eso se ha dicho que la perspectiva de Danto sienta las bases para una definición institucionalista de las obras de arte (Thomas, 2018). En síntesis, las circunstancias que rodean una obra son esenciales para comprenderla; dejándose de lado la ilusión de que el sentido de la misma puede depender de sus atributos intrínsecos.

Nuevamente, esta perspectiva según la cual para comprender una obra de arte es necesario atender al mundo que la rodea comparte algunos aspectos con nuestra propuesta: la irrelevancia de las intenciones cartesianas del artista, la dependencia de una perspectiva atributiva y la dependencia de múltiples factores que influyen en la interpretación.

Finalmente, en la introducción de este artículo señalamos que nuestra propuesta presenta afinidades generales con el constructivismo, aunque escapa de los objetivos y la extensión del presente trabajo la tarea de especificar de modo preciso cómo se vincula con otras teorías constructivistas existentes. Baste aquí señalar que, si bien sostenemos que el sentido de las obras de arte depende de la adopción de una perspectiva interpretativa por parte de los espectadores, por lo que se trata, en algún sentido, de una construcción, (1) esta es una construcción que toma en cuenta las intenciones del artista —entendidas de forma no cartesiana - (la relevancia de las intenciones en este sentido específico fue lo que quisimos sugerir con el experimento mental del gato montajista) y (2) no se trata de un constructivismo "radical", en la medida en que sostenemos que hay interpretaciones objetivamente más adecuadas que otras. Con respecto a (2) podemos utilizar la expresión de Gaut (2010) para sostener que se sigue manteniendo cierto tipo de "detectivismo", en la medida en que la construcción de quien interpreta tiene un alto grado de constreñimiento dado por la obra misma y las circunstancias que la rodean.

En ese sentido, si bien nuestra propuesta guarda, como señalamos anteriormente, algunas afinidades con la de Goodman, le otorga un lugar menos preponderante a la libertad creativa de quien interpreta. Así, mientras que para el filósofo estadounidense "reconocer patrones es, en gran medida una cuestión de inventarlos e imponerlos" (Goodman 1978, p.43), desde la perspectiva dennettiana, los patrones son, en alguna medida, reales (Dennett 1991) y, si bien hay cierto grado de indeterminación, la obra misma y el mundo que la rodea restringen en gran medida los significados que se pueden llegar a imponer. ${ }^{12}$ 


\section{La actitud de la obra de arte}

Como ya se expuso en la sección 2.a, en su teoría de los sistemas intencionales, Dennett presenta las actitudes física, del diseño e intencional. Según lo que estamos sosteniendo, la actitud que adoptamos al enfrentarnos a una obra de arte funcionaría como un subtipo de la actitud intencional. Esto quiere decir que se trata de una estrategia de interpretación en la que el objeto a interpretar es considerado el producto de un conjunto de comportamientos intencionales. Concretamente, las obras de arte son entendidas, desde esta actitud, como el producto de una serie de comportamientos realizados deliberadamente por un agente que quería transmitir algo. En otros términos, el supuesto que sustenta la interpretación realizada desde la actitud de la obra de arte es que el objeto a interpretar es el resultado de cierto tipo de agencia intencional; más precisamente, que alguien lo creó con el objetivo de transmitir algo a una audiencia. Esta propuesta no niega que un espectador que cuente con información como la de quién fue el artista creador de la obra, a qué corriente estética o estilística adhiere y en qué momento histórico la elaboró, pueda realizar una interpretación distinta y completamente legítima, incorporando estos elementos ${ }^{13}$, pero sí afirma que no es necesario contar con estos conocimientos para realizar una operación más básica y general, adoptando la actitud de la obra de arte.

Uno de los desafíos de situar a las interpretaciones artísticas como un subtipo de las interpretaciones que realizamos en el marco de la actitud intencional propuesta por Dennett es que las estrategias interpretativas que se llevan a cabo adoptando dicha actitud descansan en supuestos de optimalidad. Concretamente, las acciones analizadas desde el punto de vista de la actitud intencional son entendidas como algo que mantiene un vínculo racional con las creencias y deseos atribuidos a ese agente. En ese marco, aunque el intérprete no conozca al agente en cuestión, si está observando un producto de un comportamiento suyo sin que él esté presente, podría realizar esta interpretación, tomándose la licencia de realizar ciertas atribuciones muy generales acerca de sus creencias y deseos. Estas atribuciones podrían estar vinculadas al supuesto de que el autor en cuestión es un ser humano que habita el mismo planeta, que tiene similares modos de vida y, en el caso de determinadas obras de arte, que comparte con los intérpretes un momento histórico y una cultura. Eso sería diferente a conocer quién es el realizador, qué lugar ocupa esta realización dentro de la totalidad de su obra, dentro de qué corriente artística se ubica, de qué autores se considera heredero, etc. Todos estos insumos serán tomados en cuenta por alguien que quiera realizar una interpretación más compleja. Pero, según lo que queremos defender, es suficiente este grado de generalidad para tener una aproximación a la obra de arte en la que la misma adquiera significados en cuanto tal.

En sintonía con la delimitación trazada, Bullot \& Reber (2013) han elaborado la noción de actitud del diseño artístico [artistic design stance], que guarda algunas si- 
militudes con lo que aquí damos en llamar la actitud de la obra de arte. La actitud del diseño artístico es la estrategia de interpretación que utilizan los apreciadores de una obra en la medida en que son sensibles a su contexto específico de emergencia. El concepto de Bullot \& Reber intenta capturar el proceso que llevan a cabo apreciadores informados (especialmente críticos y conocedores de determinadas corrientes artísticas) cuando interpretan obras poniéndolas en vínculo con sus contextos históricos de surgimiento y las corrientes artísticas a las que pertenecen. Si bien estas formas de atribuir significado son compatibles con las que presentamos en este artículo, las mismas ocupan aquí un lugar periférico, dado que, según nuestra propuesta, la atribución de sentido que resulta más relevante para que la obra adquiera significado en cuanto tal (junto a las interpretaciones realizadas desde niveles más básicos, como la percepción estética), es la que se realiza adoptando la actitud de la obra de arte. Pero, como vimos, la adopción de la misma hace referencia a un proceso más general y abstracto que a los que alude la actitud del diseño artístico, para el cual no es necesario tener conocimientos de historia del arte, dado que consiste simplemente en tener en cuenta que la obra en cuestión ha sido realizada por un agente intencional con el objeto de transmitir un mensaje. Se trata entonces de dos estrategias interpretativas distintas, pero que no son incompatibles: una teoría del significado que entienda que el mismo que se conforma por distintos tipos de interpretaciones puede acoger a las dos, explicando cómo se atribuyen sentidos con diferentes niveles de especificidad.

Una implicancia de la teoría del significado de las obras de arte que estamos sugiriendo es que su componente intencionalista refiere a las intenciones que se pueden atribuir desde una perspectiva interpretativa y no a intenciones reales. En este aspecto, la perspectiva aquí presentada se asemeja al intencionalismo hipotético. ${ }^{14}$ Ahora bien, ¿quien suscribe a una teoría de este tipo debería aceptar la posibilidad de que existan obras de arte sin autores?

Consideremos el ejemplo de un carrito de limpieza olvidado en medio de una sala de un museo de arte contemporáneo por un miembro del personal de mantenimiento. Podemos imaginar (la historia ya es conocida), que los visitantes lo confunden con una obra y se quedan observándolo y fotografiándolo. En un marco en el que las fronteras de lo que se considera artístico se han ampliado enormemente desde la aparición de las primeras vanguardias artísticas hasta ahora, no es difícil pensar que un objeto depositado azarosamente en el lugar equivocado puede adoptar significados sustantivos para quien lo interpreta. La actitud de la obra de arte permitiría explicar mejor este fenómeno: estos significados emergen sólo porque los observadores suponen que hay un autor detrás.

Ahora bien, el carrito de limpieza no es presentado como una obra de arte por parte de ningún autor, razón por la cual es muy probable que, una vez aclarado el malentendido, los significados asignados se desvanezcan y los observadores sigan su camino pensando que estaban confundidos. Lo que pretende ilustrar el ejemplo es 
que desde una teoría del significado de las obras de arte basada en una perspectiva de la intencionalidad derivada se entiende que parte del significado es atribuido en virtud de que el espectador asume que ese objeto fue creado (o depositado en ese contexto) por un agente, con el fin de comunicar algo a una audiencia; por eso un mismo objeto puede adoptar significados diferentes en virtud de cual sea el marco interpretativo adoptado. En otros términos, el significado no es intrínseco al objeto. ${ }^{15}$

Por otra parte, la pregunta de si la propuesta de este artículo implica que pueden existir obras de arte sin autores cobra especial relevancia en la actualidad, dado que existen muchos programas de computadora diseñados para crear obras de arte. ${ }^{16}$ Dejando de lado la compleja y extensa discusión acerca de este llamativo fenómeno, nos limitaremos a señalar algunos compromisos que se siguen de los fundamentos que hemos defendido a la hora de considerar casos de ese tipo. Desde nuestra perspectiva, las creaciones en cuestión contarían con el mismo tipo de significado que una obra de arte corriente sólo en la medida en que haya intérpretes dispuestos a considerar a dichos programas como agentes intencionales. No es casual que los desarrolladores de estos programas, a la hora de buscar la aceptación de los productos artísticos que los mismos crean, los hayan presentado atribuyendo falsamente su autoría a agentes humanos. Todas estas consideraciones tienen que ver con nuestras prácticas interpretativas. La diferencia entre un poema escrito por un algoritmo computacional y uno escrito por una persona estaría dada porque nosotros nos comportamos frente a ellos de una forma diferente (quizá por buenos motivos), y no porque su contenido intencional provenga de un artefacto dotado de intencionalidad derivada, en un caso, y de una mente intrínsecamente intencional, en el otro. ${ }^{17}$

A su vez, es preciso señalar que las prácticas interpretativas están sujetas a la historia. Así, en este artículo señalamos que nos comportamos de forma diferente frente a un poema escrito por una persona y uno escrito por un algoritmo computacional, pero puede que esto cambie en unos pocos años (por ejemplo, si empezaramos a considerar a determinados robots como personas no humanas). ${ }^{18}$

La cuestión de si puede haber obras de arte producidas por algoritmos computacionales nos lleva a considerar una propuesta similar a la de la actitud de la obra de arte, elaborada por Linson (2013). En un artículo destinado a pensar la intencionalidad en el arte realizado por máquinas, este autor propone lo que da en llamar actitud expresiva. Esta propuesta apunta a dar cuenta del proceso interpretativo que se pone en juego cuando nos encontramos frente a alguien (o algo) que está produciendo una obra de arte, por caso, frente a un músico de jazz ejecutando una improvisación. En los términos de Linson (2013), adoptar la actitud expresiva consiste en tratar a la "situación humana" implicada en la producción de una obra de arte, como el trasfondo con respecto al cual hay que interpretar algunos de los elementos que la constituyen. Linson elabora esta noción con el objeto de poder captar ciertos elementos que escapan al enfoque racional de la actitud intencional. Desde su perspectiva, muchas 
decisiones que toma un artista cuando está creando no tienen que ver con la racionalidad, sino que están vinculadas al conocimiento técnico que adquieren los expertos en sus áreas de especialización.

Para defender su propuesta, Linson introduce el elemento de las escalas temporales que se utilizan en la interpretación de otras personas. Establece una distinción entre micro, meso y macroescala. Mientras que la escala macro es la de la vida entera de un organismo, la mesoescala hace referencia a una acción u obra completa y la microescala a las decisiones puntuales que ocurren cuando se efectúan dichas acciones. Linson argumenta que, desde la teoría de Dennett, la actitud intencional implica que todos los elementos de la microescala encuentran su sentido exclusivamente en virtud de estar inscriptos en la mesoescala. ${ }^{19}$ Linson señala que, sin embargo, tomamos las acciones de la microescala como significativas, incluso cuando las abstraemos de la mesoescala y cuando no están al servicio de una acción intencional racional. Adoptar la actitud expresiva permitiría otorgar sentido a estos elementos de carácter puntual que forman parte de la creación artística. ${ }^{20}$ Especificando la definición que dimos anteriormente sobre la actitud expresiva, los eventos que ocurren en la microescala deben ser interpretados utilizando como trasfondo a la "situación humana" implicada en la producción de la obra.

Si bien creemos que Linson tiene razón con respecto a las limitaciones de la utilización de la actitud intencional para interpretar la producción de las obras de arte, la tesis que hemos formulado respecto de la actitud de la obra de arte se diferencia de su propuesta al menos en dos aspectos. Por una parte, la actitud expresiva y la actitud de la obra de arte se diferencian en relación al tipo de fenómenos que pretenden interpretar. Mientras que la primera es una propuesta relativa a la interpretación de la producción de una obra de arte, la segunda apunta a la recepción de las mismas. Por otra parte, la perspectiva de la actitud expresiva pretende incorporar, principalmente, elementos de carácter técnico que se adquieren a partir del entrenamiento en las diferentes disciplinas. Desde el punto de vista que defendemos en este artículo, dichos elementos son muy importantes, pero no son suficientes para explicar todos los componentes relevantes en la interpretación artística. Concretamente, creemos que hay elementos que adquieren su significado en virtud de factores no técnicos (políticos, culturales, éticos, etc.) que intervienen tanto en la producción como en la recepción de las obras.

Ahora bien, si bien nuestra propuesta y la de Linson son bastante diferentes por estas razones, consideramos que no son excluyentes entre sí. Antes bien, se trata de perspectivas que pueden resultar complementarias. Las dos incorporan aspectos que no están presentes en la teoría de Dennett, pero que constituyen ampliaciones y no objeciones a sus lineamientos principales. 


\section{Conclusión}

En este trabajo hemos realizado un análisis de las implicancias de sostener una perspectiva de la intencionalidad derivada a la hora de elaborar una teoría sobre el contenido semántico de las obras de arte. Según nuestros argumentos, una teoría sobre el sentido de las obras de arte consecuente con dicha perspectiva debería compartir algunos rasgos con las teorías intencionalistas y diferenciarse de ellas en otros. Con respecto a este segundo aspecto, hemos señalado que las teorías intencionalistas disponibles descansan en una concepción cartesiana de lo mental que entra en contradicción con la perspectiva aquí propuesta. Ahora bien, si se adopta la perspectiva de la intencionalidad derivada no todos los aspectos del intencionalismo deben ser rechazados. Si bien Dennett (1990) realiza una fuerte crítica al intencionalismo, hemos argumentado que dicha crítica ataca de forma certera la idea, presente en las teorías intencionalistas, de que los contenidos de las intenciones del artista están determinados por hechos profundos, empero, la misma no tiene por qué estar presente en toda teoría intencionalista. Así, sería posible construir una teoría del significado de las obras de arte que esté asentada en la perspectiva de la intencionalidad derivada y que, al mismo tiempo, incorpore un aspecto determinado del intencionalismo (aquel que señala que parte del sentido de la obra se deriva del hecho de que la misma fue producida por un agente con intenciones). La compatibilidad entre la perspectiva de la intencionalidad derivada (en algunos aspectos anti-intencionalista, Dennett, 1990) y este aspecto intencionalista está asentada en que el rechazo de concebir a los estados mentales como determinados por hechos profundos no implica abandonar la noción misma de estados mentales. Así, desde un realismo moderado acerca de los estados mentales, a lo Dennett, se pueden seguir atribuyendo intenciones, aunque las mismas carezcan de algunas de las características que tendrían de acuerdo con una concepción cartesiana. Con el experimento mental del gato montajista hemos intentado mostrar cuáles son los aspectos de la interpretación de una obra de arte que están presentes en un abordaje intencionalista de la misma y que se pierden al adoptar una visión completamente anti-intencionalista. Luego, hemos señalado que la estrategia interpretativa que da cuenta de este tipo de atribuciones podría recibir el nombre de actitud de la obra de arte.

La actitud de la obra de arte debe ser entendida como un subtipo de la actitud intencional y consiste en abordar determinados objetos suponiendo que un agente los creó intencionadamente, con el objetivo de transmitir algo. Dicha actitud es una entre otras estrategias atributivas posibles que se adoptan en la interpretación de las obras de arte. Así, el concepto de actitud de la obra de arte es bien alojado por una teoría que sostendría que el significado de estos complejos ítems culturales es parcialmente indeterminado, relativo a una historia y dependiente de una atribución interpretativa; aspectos que deberían estar presentes en toda teoría del significado 
de las obras de arte desde una perspectiva de la intencionalidad derivada.

\section{Referencias}

Arnheim, R. 1962. Picasso's Guernica. Berkeley: University of California Press.

Beardsley, M. 1981. Aesthetics, problems in the philosophy of criticism. Indianapolis: Hackett Publishing.

Boden, M. 2004. The creative mind: Myths and mechanisms. United Kingdom: Routledge.

Brentano, F. 1995 [1874]. Psychology from an Empirical Standpoint. London: Routledge.

Briskman, L. 1980. Creative product and creative process in science and art. Inquiry 23(1): 83-106.

Bullot, N. \& Reber, R. 2013. The artful mind meets art history: Toward a psycho-historical framework for the science of art appreciation. Behavioral and brain sciences 36(2): 12337.

Carroll, N. 1997. The intentional fallacy: Defending myself. The Journal of Aesthetics and Art Criticism 55(3): 305-9.

Carroll, N. 2000. Interpretation and intention: The debate between hypothetical and actual intentionalism. Metaphilosophy 31(2): 75-95.

Clark, A. 2002. That Special Something: Dennett on the Making of Minds and Selves. En: A. Brook and D. Ross (eds.) Daniel Dennett, Cambridge: Cambridge University Press, p.187205.

Cope, D. 2004. Virtual music: computer synthesis of musical style. Cambridge: The MIT press.

Currie, G. 1995. Image and mind: Film, philosophy and cognitive science. Cambridge: Cambridge University Press.

Danto, A. 1964. The artworld. The journal of philosophy 61(19): 571-84.

Danto, A. 1981. The Transfiguration of the Commonplace. Cambridge: Harvard University Press.

Davies, D. 2009. The Artistic Relevance of Creativity. En: Krausz, M., Dutton, D.; Bardsley, K. (eds.) The Idea of Creativity. Netherlands: Brill, p.213-34.

Dawkins, R. 1976. The selfish gene. Oxford: Oxford university press.

Dennett, D. 1998 [1987]. La actitud intencional. Trad. Zadunaisky. Barcelona: Gedisa.

Dennett, D. 1990. The interpretation of texts, people and other artifacts. Philosophy and phenomenological research 50: 177-94.

Dennett, D. 1991. Real patterns. The journal of Philosophy 88(1): 27-51.

Dennett, D. 1995. Darwin's dangerous idea. New York: Simon y Schuster, Inc.

Farrell, J. 2017. The Varieties of Authorial Intention: Literary Theory Beyond the Intentional Fallacy. Cham: Springer.

Gardner, H. 1970. Children's sensitivity to painting styles. Child Development 41(3): 813-21.

Goodman, N. 1976. Languages of Art: An Approach to a Theory of Symbols, 2nd edition. Indianapolis: Hackett Publishing Company.

Goodman, N. 1990 [1978]. Ways of Worldmaking. Madrid: La balsa de la medusa.

Gaut, B. 2010. A philosophy of cinematic art. Cambridge: Cambridge University Press.

Hirsch, E. 1967a. Validity in Interpretation. New Haven, CT: Yale University Press.

Hirsch, E. 1967b. In defense of the author. En: Iseminger (ed.) (1992), p.11-23. 
Haugeland, J. 1998. Having thought. Cambridge: Harvard University Press.

Iseminger, G. (ed.) 1992. Intention and interpretation, Philadelphia: Temple University Press. Iseminger, G. 1996. Actual intentionalism vs. hypothetical intentionalism. The journal of aesthetics and art criticism 54(4): 319-26.

Levinson, J. 1996. The pleasures of aesthetics: Philosophical essays. New York: Cornell University Press.

Linson, A. 2013. The expressive stance: Intentionality, expression, and machine art. International Journal of Machine Consciousness 5(2): 195-216.

Lyas, C. 1992. Wittgensteinian intentions. En: Iseminger (ed.) (1992), p.132-51.

Machotka, P. 1966. Aesthetic criteria in childhood: Justifications of preference. Child Development 37(4): 877-85.

Nünning, V., Nünning, A. \& Neumann, B. (eds.) (2010). Cultural ways of worldmaking: Media and narratives (Vol.1). Walter de Gruyter.

Quine, W. 1969 [1960]. Word and object. Cambridge: Technology Press of Massachusetts Institute of Technology.

Searle, J. 1982. The myth of the computer. The New York Review of Books 29(7): 3-6.

Searle, J. 1992 [1983]. Intencionalidad: Un ensayo en filosofía de la mente. Madrid: Tecnos.

Spingarn, J. 1984 [1924]. Criticism in America. New York: Core Collection Micropublications.

Thomas, A. 2018. The Definition of Art. The Stanford Encyclopedia of Philosophy (Fall 2018), Edward N. Zalta (ed.) https://plato.stanford.edu/archives/fall2018/entries/art-definition.

Tolhurst, W. 1979. On what a text is and how it means. The British Journal of Aesthetics 19(1): 3-14.

Wimsatt, W. \& Beardsley, M. 1946. The intentional fallacy. The Sewanee Review 54(3): 468-88.

Wreen, M. 2014. Beardsley's Aesthetics. The Stanford Encyclopedia of Philosophy (Winter 2014 Edition), Edward N. Zalta (ed.) https://plato.stanford.edu/archives/win2014/entries/ beardsley-aesthetics $(21 / 01 / 2020)$

\section{Películas}

Antunes, J. 2017. Baronesa, Brasil.

Loznitsa, S. 2016. Austerlitz, Alemania.

\section{Notas}

${ }^{1}$ Tomaremos la noción 'contenido semántico' según su acepción más general, que incluye diversos tipos de fenómenos intencionales y dentro de la cual se puede incluir el significado de las obras de arte. Las nociones 'contenido semántico', 'significado’ y ‘sentido' serán utilizadas de manera intercambiable.

${ }^{2}$ Si bien el término 'intencionalismo' podría ser consignado en bastardillas por tratarse de un término teórico con un significado específico, hemos decidido no hacerlo dado que la expresión es muy similar a 'intencionalidad', que también se utiliza con frecuencia en el artículo pero que tiene un significado diferente. Así, para facilitar la lectura, decidimos usar 'intencionalismo' sin bastardillas, acercándolo al uso de 'intención', propio del lenguaje habitual, 
del que deriva, y diferenciarlo de las expresiones 'intencionalidad' y 'sistemas intencionales', cuyo significado es eminentemente técnico, que serán usados en bastardillas.

${ }^{3} \mathrm{El}$ mismo recorte, que consiste en abordar la cuestión de la interpretación discutiendo con las teorías intencionalistas disponibles es realizado también por distintos compendios (Iseminger Ed. 1992), libros (Farrel 2017) y entradas enciclopédicas (https://www.iep.utm.edu/ artinter/\#H1) destinadas al tema.

${ }^{4} \mathrm{El}$ hecho de que, con el fin de simplificar, nos refiramos a él como "el experimento del gato montajista" no debe hacernos perder de vista que, en el experimento propuesto, el momento de registro realizado por la cámara de seguridad es tan importante como el de edición, realizado por el procedimiento del gato.

${ }^{5}$ La etiqueta de "realismo moderado" que se aplica a la teoría de los estados mentales de Dennett procura subrayar que se trata de una teoría menos realista que el "realismo de vigor industrial" de Fodor y un poco menos realista que el realismo, también moderado, de Davidson (Dennett 1991). Por una parte, se diferencia del realismo fodoriano dado que este asume que tener estados mentales es tener estados internos que se individualizan funcionalmente de modo isomórfico a aquellos (Fodor 1985), supuesto que Dennett considera erróneo e innecesario. Por otra parte, Dennett diferencia su teoría de la de Davidson por considerar que este no le da un lugar relevante a la tesis de la indeterminación de la traducción radical (Quine 1969). Mientras que para Davidson dicha tesis constituye una posibilidad teórica sin consecuencias relevantes, Dennett contempla en su teoría la posibilidad de que dos interpretaciones rivales, con diferencias sustanciales entre sí, sean igualmente adecuadas para describir un mismo conjunto de conductas.

${ }^{6} \mathrm{El}$ mayor exponente de este enfoque es Searle $(1982,1992)$, quien además defiende que la distinción entre la intencionalidad original y la derivada se sostiene porque la intencionalidad mental es de carácter intrínseco. Sin embargo, decidimos utilizar esta etiqueta más amplia porque la tesis de la intencionalidad original es sostenida por muchos autores contemporáneos (Fodor, Dretske, etc.) y porque consideramos que, en general, viene acompañada de otras tesis asociadas, que en el emblemático texto de Haugeland (1990) son reconocidas como cartesianas. En los términos de Haugeland (1990), los jugadores de la primera base, también llamados 'cartesianos', son los que sostienen que la intencionalidad original es la provincia exclusiva de los estados mentales con contenido (cfr. p: 132, la bastardilla es nuestra).

${ }^{7}$ Para defender esta afirmación, Wimsatt \& Beardsley toman como ejemplo a Spingarn, un defensor del intencionalismo que ha sostenido, por ejemplo: "El objetivo del poeta debe ser juzgado en el momento del acto creativo, es decir, por el arte del poema mismo." (Spingarn 1984 [1924], p.24-5).

${ }^{8}$ Esta expresión elaborada por Iseminger (1996) y retomada por autores como Noël Carroll (2000) hace referencia al famoso personaje Humpty Dumpty del libro "A través del espejo y lo que Alicia encontró allí" de Lewis Carroll. En un diálogo con Alicia, Humpty Dumpty sostiene que cuando él usa una palabra, la misma significa precisamente lo que él decide que signifique, aunque se trate de una utilización del lenguaje completamente caprichosa y alejada del uso habitual.

${ }^{9}$ Para una discusión acabada de estos tópicos se recomienda consultar el compendio Intention and interpretation editado por Iseminger (1995).

${ }^{10}$ Un ejemplo de uno de estos "accidentes felices", puede encontrarse en la película Baro- 
nesa, de Juliana Antunes (2017). La película trata sobre una mujer que vive en una favela en Brasil. Si bien se trata de una ficción, esta película está filmada en el lugar en el que efectivamente habita este personaje, que en algún punto es indiscernible de la actriz que lo representa, Andeia Pereira De Sousa. En una de las tomas que ocurre en el exterior de la casa de la protagonista, se empieza a escuchar un tiroteo. Las actrices interrumpen lo que están haciendo y, con un gesto de miedo corren a refugiarse en el interior de la casa. Esto se ve de forma entrecortada, porque, en el medio de este proceso, la cámara se cae al piso, y los pies de la directora se unen a los de las actrices en la corrida al refugio. Es una decisión de montaje incluir esta secuencia en la película, pero la mayoría de los espectadores atentos y exentos de cinismo no tienen dudas de que esa escena no formaba parte de ningún guion.

${ }^{11}$ En esta exposición esquemática que analiza los contenidos de una obra en función de una contraposición entre intenciones y accidentes se están dejando de lado factores que no entran en ninguna de las dos categorías, como la experiencia acumulada, las habilidades, los prejuicios u otros pensamientos inconscientes del autor, que explican contenidos de la obra y no constituyen intenciones. Dejamos de lado esta posible crítica a las perspectivas intencionalistas, para poder puntualizar mejor los principales problemas que creemos que tiene esta perspectiva. Sin embargo, consideramos que la propuesta que presentamos en los apartados 5 y 6 da lugar a un abordaje al que no se le escapan estos matices.

${ }^{12}$ Para respaldar esta comprensión de la teoría de Goodman como un constructivista "radical" se puede ver Nünning; Nünning \& Neumann (2010).

${ }^{13}$ Este tipo de interpretación formaría parte de lo que Bullot \& Reber (2013) llaman la actitud del diseño artístico. Como explicaremos más adelante, la actitud de la obra de arte y la actitud del diseño artístico apuntan a procesos diferentes, pero no contradictorios, por lo que ambas pueden ser bien acogidas por una teoría pluralista del significado de las obras de arte.

${ }^{14}$ Puede resultar aclarador recordar que, a pesar de esta similitud, la perspectiva propuesta en este artículo se distingue del $I H$ por motivos relevantes. En primer lugar, según nuestra propuesta, las atribuciones realizadas a partir de la adopción de la actitud de la obra de arte conviven con otras atribuciones que fueron realizadas al abordar la obra de otros modos: a partir de la percepción estética más inmediata, atendiendo a las narraciones que incluye, etc. Por otra parte, el modo de entender a las intenciones atribuidas es diferente: ya no se espera que sean de carácter determinado. En este aspecto, nuestra propuesta entiende que el límite para conocer cuál es la mejor interpretación de una obra no es siempre un problema epistemológico, sino que, en algunos casos, la cuestión de cuál es la mejor de dos interpretaciones rivales será indeterminada en el plano ontológico.

${ }^{15}$ Nuevamente, esto está en concordancia con la propuesta de Goodman, que invita a cambiar la pregunta de “¿qué es el arte?” por la de “¿cuándo hay arte?”. Así, desde su perspectiva, resulta aceptable que "una cosa puede funcionar como obra de arte en algunos momentos y no en otros" (Goodman 1978, p. 98).

${ }^{16}$ En Boden (2004) se encuentran análisis de algunos casos sugerentes.

${ }^{17}$ Alguien podría pensar que en estos casos la creación del "algoritmo computacional artista" es, en sí misma, una obra de arte, que tiene un autor en un sentido convencional. La discusión sobre el significado que estamos queriendo llevar adelante no gira en torno al sentido del "algoritmo computacional artista" como obra de arte, sino de las obras que dicho algoritmo produce. Lo mismo podría decirse del experimento del gato montajista. Lo que nos interesa es si el producto que da como resultado dicho experimento, sin añadir ningún 
tipo de curaduría ulterior, es en sí mismo una película. Esto permite ver por qué a la hora de considerar la película (o poema o composición) como obra de arte resulta irrelevante el hecho de que, en última instancia, alguien haya diseñado el experimento (o programado el algoritmo): en esos casos el diseñador del experimento (o programador) no es responsable del contenido semántico de la película de un modo convencional. La intuición que buscamos despertar es que no nos comportamos del mismo modo frente a estos objetos que frente a aquellos que sabemos que han sido diseñados de un modo directo por un autor $-\mathrm{O}$ al menos curados posteriormente.

Los casos que resultan relevantes para pensar esto son aquellos en los que la programación se encuentra desacoplada del contenido final de la obra (y no tanto ejemplos en donde el programador es responsable de modo más directo dicho contenido). Piénsese, por ejemplo, en un algoritmo programado para escribir poemas utilizando como insumo textos que encuentra de manera aleatoria en Internet.

${ }^{18}$ Uno de los revisores de este artículo elaboró la siguiente situación hipotética: Imaginemos que un museo exhibe una exposición artística realizada con ilustraciones que fueron producidas por un algoritmo computacional. En la primera versión de esta situación hipotética las personas que asisten a la exposición ven el nombre de quien realizó las obras y, sin saber que se trata de un algoritmo, se vinculan con ellas del mismo modo que lo harían si se tratara de ilustraciones producidas por una persona. Hasta aquí, las consideraciones están en concordancia con lo defendido en nuestro artículo, dado que estos sentidos emergen, en parte, en virtud de que los espectadores asumen que hay un autor que las produjo intencionalmente. En una segunda versión de esta situación hipotética presentada por el revisor, los espectadores saben que el autor de las ilustraciones es, en realidad, un algoritmo computacional. El revisor sostiene que esto no alteraría el estatus de las mismas como obras de arte y señala que, después de todo, la exposición probablemente tenía el trabajo de un curador, que organizó y ordenó la exposición de las obras. Con respecto a esto debemos señalar que, por una parte, lo sostenido en este artículo respecto del significado de las obras de arte no pretende proveernos de criterios necesarios y suficientes para trazar una delimitación precisa que separe las producciones que deben ser consideradas obras de arte de las que no lo son. En ese sentido, la concepción del sentido de las obras de arte desde la perspectiva de la intencionalidad derivada implica dejar de lado la aspiración de determinar con precisión, en todos los casos, qué es una obra de arte y qué no lo es. Por otra parte, la situación planteada por el revisor resulta enriquecedora en la medida en que indica un caso que se encuentra justo en una zona intermedia de la diferencia que queremos trazar. Mientras que, por una parte, en las obras que suponemos que elaboró un artista están presentes las interpretaciones realizadas adoptando la actitud de la obra de arte y que, por otra parte, en el producto que resulta del experimento del gato montajista no lo están, las obras expuestas en este museo se encuentran en una posición intermedia. Podría pensarse que, dado que las personas reciben las obras asumiendo que hay detrás un trabajo de curaduría, parte de las interpretaciones que surgen al pensar que detrás hay un agente intencional que quiso transmitir algo, estará presente incluso aunque no haya autor.

${ }^{19}$ En términos musicales, esto implicaría que una nota en un determinado lugar de la melodía puede ser analizada en función de si cumple o no cumple ciertas reglas (de armonía, de estructura, etc.), pero dicha interpretación no puede dar cuenta de la diferencia entre la nota que efectivamente se ejecutó y cualquiera de las otras que también hubieran respetado 
las reglas de composición y que no fueron elegidas.

${ }^{20}$ Gracias a ella podríamos capturar, por ejemplo, la nota musical específica que un músico decidió ejecutar, que es una entre otras posibles que hubieran cumplido de igual modo reglas de armonía y estructura.

\section{Agradecimentos}

Esta contribución no hubiera sido posible sin la orientación en la investigación y los siempre pertinentes comentarios de la Dra. Silvia Carolina Scotto y la Dra. Laura Danón. También fueron muy relevantes los aportes de mis compañeros del grupo de investigación "Variedades de la intencionalidad: atribución, expresión y contenido" (SECYT-Universidad Nacional de Córdoba).

Asimismo, estoy enormemente agradecida con el crítico y programador de cine Roger Alan Koza, que brinda un importante espacio de reflexión y formación en torno al cine en el Cineclub Municipal Hugo del Carril, así como con el resto de mis compañeros que asisten al curso "El deseo de ver, escuchar y saber". Si bien soy responsable de la totalidad del presente escrito, si algo de lo que sostengo con respecto al cine es correcto, es responsabilidad suya, especialmente de Roger.

Finalmente, quiero agradecer especialmente a un revisor de la revista, que realizó significativos comentarios y contribuciones dirigidos a vincular de modo más estrecho mi trabajo con conclusiones obtenidas en el campo de la filosofía del arte. 